\title{
Epileptik Sendromlarda Göz Kapama Sensitivitesi ve Prognozla İlișkisi
}

\author{
Eye Closure Sensitivity and Prognosis in Epilepsy Syndromes
}

Mustafa Aykut Kural1, Mine Hayriye Sorgun¹, Ferda Selçuk², Aytaç Yiğit ${ }^{3}$ 'Department of Neurology, Ankara University School of Medicine,
ibni Sina Hospital, Samanpazarr, Ankara, Turkey
2 Clinic of Neurology, Dr. Burhan Nalbantoğlu State Hospital,
Nicosia, Turkish Republic of Northern Cyprus
${ }^{3}$ Bodrum, Muğla, Turkey
Geliș tarihi : 24.08.2014 • Kabul tarihi: 19.12 .2014

İetișim

Uz. Dr. Mine Hayriye SORGUN

Tel: 03125083403

E-posta:drmsorgun79@yahoo.com.tr

Ankara Üniversitesi Tıp Fakültesi İbni Sina Hastanesi, Nöroloji

Anabilim Dalı 11.Kat, Samanpazarı / ANKARA
Giriș: Bazı epilepsi hastalarında gözlemlenen göz kapama sensitivitesi, epileptik sendromunun prognozuyla ilișkili olabilir.

Hastalar ve yöntem: Göz kapama sensitivitesi bulunan yedi hastanın epileptik sendrom tanısı ve prognozla ilișkisi incelenmiștir.

Bulgular: Göz kapama sensitivitesi bulunan yedi hastamızın beșinde juvenil myoklonik epilepsi, birinde juvenil absans epilepsisi ve birinde absanslı göz kapağı myoklonisi tanıları kondu. Altı hasta düșük doz valproik asitle ve bir hasta da klonazepamla nöbet geçirmemekteydi.

Sonuç: Göz kapama sensitivitesi, juvenil myoklonik epilepsi, juvenil absans epilepsisi ve absanslı göz kapağı myoklonisi gibi idiyopatik jeneralize epilepsili hastalarda iyi prognoz göstergesi olabilir.

Anahtar Sözcükler: Göz kapama sensitivitesi, juvenil myoklonik epilepsi, juvenil absans epilepsisi, absanslı göz kapağı myoklonisi, prognoz

Aim: Eye-closure sensitivity may be observed in some patients with epilepsy and correlated to the prognosis of the epilepsy syndromes.

Patients and methods: The cases of seven patients with epilepsy demonstrating eye-closure sensitivity were reviewed for the diagnosis of the epilepsy syndromes and for the association with prognosis.

Results: All patients with eye-closure sensitivity had idiopathic generalized epilepsy, as juvenile myoclonic epilepsy in five patients, juvenile absence epilepsy in one patient and eyelid myoclonia with absences in another one. Six patients were seizure-free with low doses of valproate, and one patient with clonazepam treatment.

Conclusion: Eye-closure sensitivity may be correlated with good prognosis in patients with idiopathic generalized epilepsy like juvenile myoclonic epilepsy, juvenile absence epilepsy and eyelid myoclonia with absences.

Key Words: Eye-closure sensitivity, juvenile myoclonic epilepsy, juvenile absence epilepsy, eyelid myoclonia with absences, prognosis

Göz kapama sensitivitesi (GKS), göz kapama ile ortaya çıkan bilateral diken-dalga aktivitesi olarak tanımlanmıştır (şekil) ve rutin EEG çekimi esnasinda bazı epileptik hastalarda gözlemlenebilir (1).

Göz kapama sensitivitesi, epileptik sendromlarda iyi belgelenmiştir ama prognoz ile ilişkisi iyi anlaşılamamıştır (2-5).

\section{HASTALAR VE YÖNTEM}

Ankara Üniversitesi İbn-i Sina Hastanesi'nde Ocak 2009 ve Aralık 2012 y1lları arasinda epilepsi tanısı olan hastaların EEG kayıtlarını gözden geçirdik ve yedi hastada GKS saptadık. Hastaların klinik özellikleri tabloda özetlenmiştir.

\section{SONUÇLAR}

$\mathrm{Bu}$ nedenle, biz göz kapama sensitivitesi bulunan yedi hastanın epileptik sendrom tanılarını ve prognozla ilişkisini inceledik.
Rutin EEG kayıtlarında GKS bulunan yedi epileptik hastanın ortalama yaşı 17 (aralık 14-33 yaş), ortalama nöbet başlama yaşı ise 16 (aralık 11-29 yaş) idi. Hastaların dördü kadın, üçü 
erkekti. Tüm hastaların nörolojik muayeneleri normaldi. Bir hastanin özgeçmişinde febril nöbet bulunmaktaydı. Hiçbir hastanın soygeçmişinde epilepsi bulunmamaktaydi.

Hastaların beşinde juvenil myoklonik epilepsi (JME), birinde juvenil absans epilepsisi (JAE) ve birinde de absanslı göz kapağı miyoklonisi (AGM) tanısı kondu.

Altı hasta düşük doz valproik asitle ve bir hasta da klonazepamla nöbet geçirmemekteydi.

\section{TARTIȘMA}

Rutin EEG kayıtlarında, GKS sıklıkla tesbit edilen bir bulgu değildir. Biz yalnız yedi epilepsi hastasinda GKS

\section{KAYNAKLAR}

1. Duncan JS, Panayiotopoulos CP. The differentiation of 'eye closure' from 'eye closed'. In: Duncan JS, Panayiotopoulos $\mathrm{CP}$, editors. Eyelid Myoclonia with Absences. London: John Libbey Company;1996;77-87.

2. Baykan-Kurt B, Gökyiğit A, Parman Y, Kinay D, Gürses C. Eye Closure Related saptadık. Bunların beşinde JME, diğer ikisinde JAE ve AGM tanısı koyduk. Hastalarımızın nöbetleri düşük doz valproik asit ve klonazepam ile kontrol altına alınmıştır.

Baykan-Kurt ve arkadaşları GKS olan 10 hasta bildirmişlerdir. $\mathrm{Bu}$ hastaların beşinde JME, üçünde AGM, birinde JAE ve diğerinde çocukluk çağ1 absans epilepsisi vardi. JME'li hastalarda düşük-orta doz valproat ile nöbet kontrolü kolaylıkla sağlanırken, AGM olan hastada valproat yanit1 göreceli olarak zayıftı (2).

Sevgi ve arkadaşları GKS'si olan 26 hasta sunmuşlardır. Altı hastada AGM, alt1 hastada JME, dört hastada tonikklonik nöbetli idiyopatik jeneralize epilepsi, bir hastada JAE ve dokuz hastada idiyopatik oksipital lob

Spike and Wave Discharges: Clinical and Syndromic Associations. Clin Electrencephalogr 1999;30:106-110.

3. Sevgi EB, Sayg1 S, Ciger A. Eye closure sensitivity and epileptic syndromes: A retrospective study of 26 adult cases. Seziure 2007;16:17-21. epilepsi olduğu bildirilmiştir. Tüm hastaların nöbetleri kontrol altındadir (3).

Guaranha ve arkadaşları, 65 JME'li hastanin 13'ünde GKS göstermişlerdir. Dört hasta tedaviye iyi yanıt vermemiştir. $\mathrm{Bu}$ nedenle JME'de GKS'nin kötü prognoz belirtisi olduğunu belirtilmiştir (4).

Tekin Güveli ve arkadaşları, 76 JME hastasinin 15'inde GKS tesbit etmişlerdir. GKS olan sadece iki hastada kötü prognoz bulunmuştur (5).

Bizim sonuçlarımız, GKS'sinin JME, JAE ve AGM gibi idiyopatik jeneralize epilepsi hastalarında kötü prognoza işaret etmediğini telkin etmektedir.

4. Guaranha MS, Filho GM, Lin K, Guilhoto LM, Caboclo LO, Yacubian EM. Prognosis of juvenile myoclonic epilepsy is related to endophenotypes. Seizure. 2011;20:42-48.

5. Tekin Güveli B, Baykan B, Dörtcan N, Bebek N, Gürses C, Gökyiğit A. Eye closure sensitivity in juvenile myoclonic epilepsy and its effect on prognosis. Seizure. 2013;22:867-871. 